

\title{
Endodontic Treatment of Mandibular Canine with Two Roots and Two Canals
}

Prashant P Moogi, Reshma S Hegde, BR Prashanth, G Vinay Kumar, Nandini Biradar

\begin{abstract}
In majority of cases, mandibular canines have one root and one root canal, although $15 \%$ may have two canals. Literature report shows incidence of two-rooted canine as low as $1.7 \%$. This article reports a clinical case of endodontic treatment of mandibular canine with two roots and two canals.
\end{abstract}

Keywords: Mandibular canine, Two roots, Two canals, Conebeam computed tomography.

How to cite this article: Moogi PP, Hegde RS, Prashanth $B R$, Kumar GV, Biradar N. Endodontic Treatment of Mandibular Canine with Two Roots and Two Canals. J Contemp Dent Pract 2012;13(6):902-904.

\section{Source of support $\mathrm{Nil}$}

Conflict of interest: None declared

\section{INTRODUCTION}

Successful root canal therapy requires a thorough knowledge of tooth anatomy and root canal morphology. ${ }^{1}$ The aim of endodontic treatment is the elimination of infection from the root canal and the prevention of reinfection. M orphologic features of tooth may also adversely affect endodontic procedures. $M$ any clinicians have the perception that a given tooth will contain a specific number of roots and/or canals. Careful evaluation of research material has shown that variations in tooth morphology are common. ${ }^{2}$ In mandibular anterior teeth, prevalence of two or three root canal has been reported to be as low as $1 \%$ and as high as $43 \% .{ }^{3} \mathrm{M}$ andibular canines are recognized as having one root and one root canal in majority of cases. The occurrence of two roots and even more than two canals is rare, ranging from 1 to $5 \%{ }^{4}$

The following is a case report of mandibular canine with separate two roots and two canals.

\section{CASE REPORT}

A 32-year-old female patient reported to Department of Conservative Dentistry and Endodontics with a chief complaint of pain in lower right anterior region from last 3 months. Clinical examination revealed mandibular right canine (43) had deep proximal caries. D iagnostic radiograph reveal ed deep proximal caries involving pulp with two roots and two roots canals (Fig. 1). Thermal and electric pulp tests showed delayed response. Patient was diagnosed with irreversible pulpitis. Cone-beam computed tomography (CBCT) was performed to confirm two separate root and root canals (Fig. 2).

Endodontic treatment was initiated after administrating local anesthesia. Rubber dam was placed and endodontic access was performed with a round diamond point bur and EndoZ tapered safe end bur (Dentsply Maillefer, Switzerland ). Negotiation of root canals was done under dental optical microscope (Carl Zeiss, USA) (Fig. 3) with a size $10 \mathrm{~K}$ file. Cervical and middle third was prepared with SX file of ProTaper system (Dentsply Maillefer, Switzerland). Root canal length was determined with an electronic A pex Locator (Root ZX, J M orita, Japan) and reconfirmed radiographically (Fig. 4). Biomechanical preparation was done up to ProTaper file size F1 using

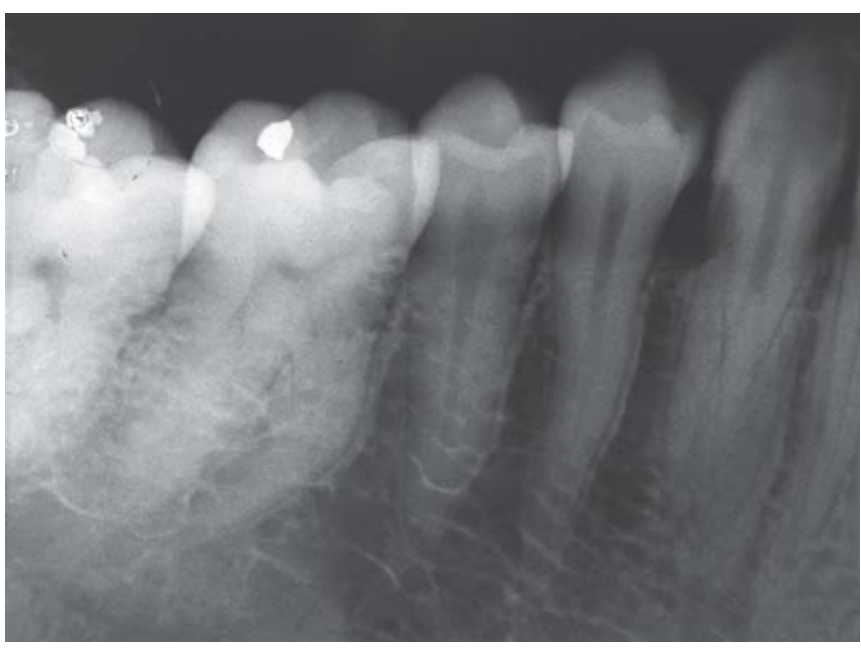

Fig. 1: Preoperative radiograph 


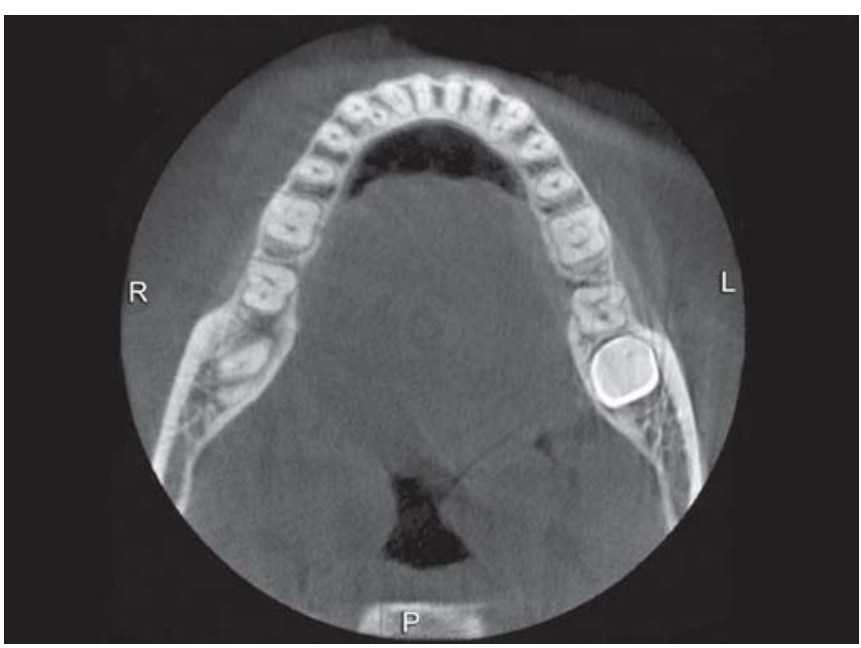

Fig. 2: Cone-beam computed tomography images

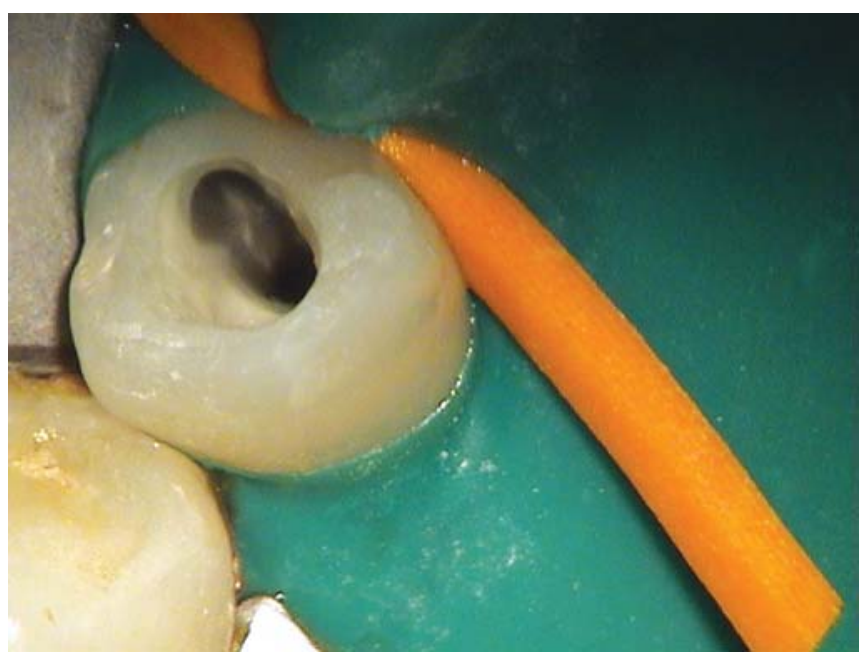

Fig. 3: Access under dental optical microscope

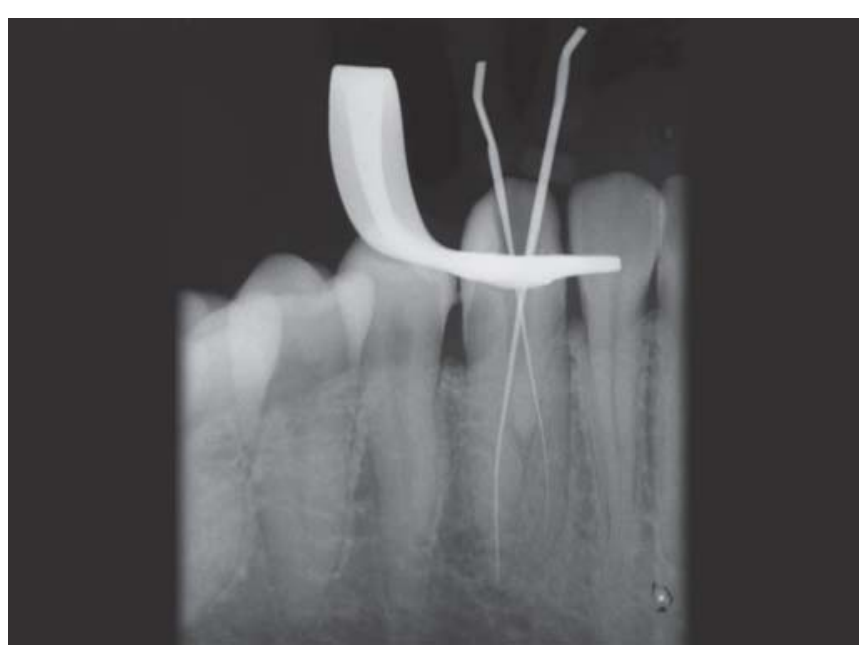

Fig. 4: Working length radiograph

EDTA lubrication (RC-Prep, D entalcompare, USA) under constant irrigation of $3 \% \mathrm{NaOCl}$ and saline at each change of file. Obturation was performed using F1 ProTaper GP cones using AH Plus Sealer (Dentsply Maillefer, Switzerland) (Fig. 5). A fter 1 week, patient reported asymptomatically and final restoration was performed.

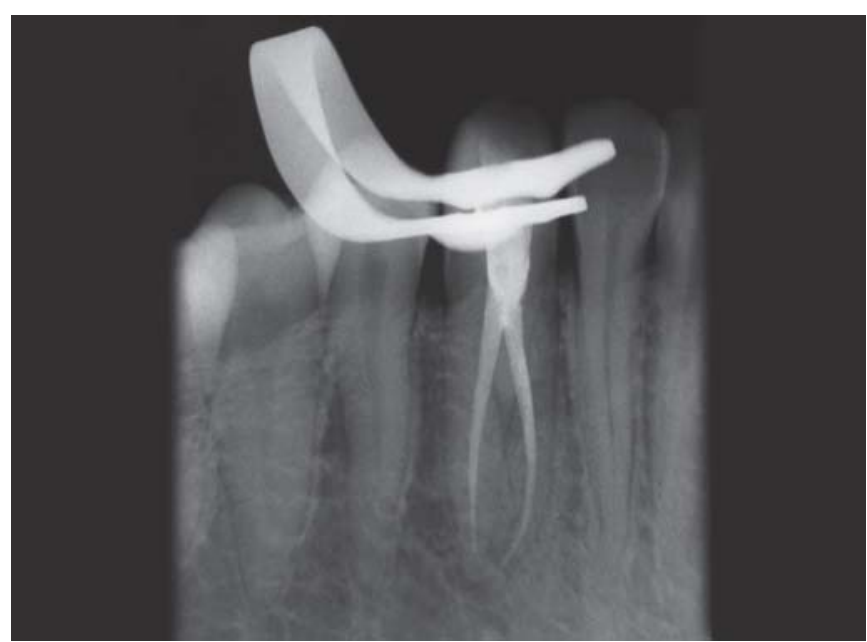

Fig. 5: Obturation radiograph

\section{DISCUSSION}

Diagnosis and identification of the number of roots and root canals are key factors for endodontic treatment. ${ }^{5} \mathrm{Good}$ quality radiographs taken at different angulations some with file in place are very helpful in finding and locating extra canals. ${ }^{6}$ A dditional root canals if not detected are major reason for failure of endodontic treatment. ${ }^{7}$

On reviewing the literature it becomes apparent that there is divergence of opinion as to the anatomy of root canal of human permanent teeth. The incidence of two root canals in single-rooted teeth has been reported to be as low as $0.0 \%$ and high as $6.25 \% .8,9$ Investigators have reported on the anatomical variations associated with mandibular canines. In a study conducted on internal anatomy of mandibular canines, analysis showed that $98.3 \%$ had only one root, $4.9 \%$ two canals and one foramen, $1.2 \%$ two canals and two foramen. Two canals and two roots were present in $1.7 \%$ of cases. ${ }^{10}$

In majority of cases, mandibular canines are recognized as usually having one root with one root canal. Our case report demonstrates mandibular canine with two separate roots and root canals. Here bifurcation of root and root canal occurred at floor or cervical $1 / 3$ which is in accordance with previous study which states bifurcation at cervical and middle third has been shown to occur in $43 \%$ of situation at these sites. ${ }^{11} 0$ ne of the recent study states root bifurcation was observed at middle third and apical thirds. ${ }^{12} \mathrm{Here}$, CBCT was used as it is more precise than periapical radiograph in confirming extra root and canals. ${ }^{13,14} \mathrm{~W}$ ith this coronal and axial view of the mandibular canine were readily produced, confirming two separate root and root canals, exact location and anatomy of root canal system could be assessed.

Case reports displaying mandibular canines with two root canals have been published earlier. ${ }^{6,4,15}$ However, 
presence of two roots in mandibular canines is rarely observed. ${ }^{4,5} \mathrm{D}^{\prime}$ A rcangelo et $\mathrm{al}^{2}$ reported two cases of endodontic treatment of mandibular canines with two roots. Victorino et al ${ }^{16}$ describes a case report of a patient with bilateral mandibular canine with two roots and two canals. Our case also demonstrates bilateral mandibular canines with two separate roots and root canals that is evident on CBCT image (Fig. 2) and is the second case reported of this type.

A rare case of root canal retreatment in mandibular canine with two roots and three canals has been described; three canals and two foramina were also recognized. ${ }^{17,18}$ All of these cases suggest aberrant morphology in root and root canals.

\section{CONCLUSION}

Failure to locate and treat extra canal is one of the most common causes for failure of root canal treatment. This case report shows presence of two separate roots and root canals in mandibluar canine. Though such anatomic findings have been cited earlier, our case report highlights the importance of having detailed knowledge of all possible root canal irregularities practitioners should look for and never assume canal systems are simple. Radiographs and magnification devices are important tools in diagnosing and treating such cases.

\section{REFERENCES}

1. Ingle JI, B ackland LK, B aumgartner JC (Eds). Ingle's Endodontics (6th ed). ON , Canada: BC Decker Inc. Publishing 2008.p.151.

2. D'A rcangelo C, V arvara G, de Faizo P. R oot canal treatment in mandibular canines with two roots: A report of 2 cases. Int Endod J 2001 J un; 34(4):331-34.

3. A lapati S, Zaatar EI, Shyama M , A I-Zuhair N. M axillary canine with two root canals. Med Princ Pract 2006;15:74-76.

4. Wang $L$, Zhang R, Peng B. Clinical features and treatment of mandibular canines with two root canals: Two case reports. Chinese J Dent Res 2009;12(1):61-62.

5. Bharadwaj A, B haradwaj A . M andibular canines with two roots and two canals. Int J Dent Clin 2011;3(3):77-78.

6. Gaikwad A. Endodontic treatment of mandibular canine with two canals- -a case report. Int J D ental Clin 2011;3(1):118-19.

7. Haapasalo M, U dnaes T, Endal U. Persistent, recurrent, and acquired infection of root canal system post-treatment. Endodontic Topics 2003 Nov;6(1):29-56.

8. Green D. Double canals in single roots. Oral Surg Oral Med Oral Pathol 1973 M ay;35(5):689-96.
9. Sikri VK, Kumar V. Permanent human canines: Configuration and deviations of root canals: A $n$ in vitro study. J Conserv D ent 2003;6(4):151-60.

10. Pécora JD, Sousa Neto MD, Saquy PC. Internal anatomy, direction and number of roots and size of human mandibular canines. B raz Dent J 1992;4(1):53-57.

11. Sharma R, Pecora JD, L umley PJ, W imsley AD. The external and internal anatomy of human mandibular canine teeth with two roots. Endod D ent Traumatol 1998 A pr;14(2):88-92.

12. Versiani M A, Pecora JD, Sousa-N eto M D. The anatomy of tworooted mandibular canines determined using micro-computed tomography. Int Endod J 2011 Jul; 44(7):682-87.

13. Patel S. N ew dimensions in endodontic imaging. Part 2. Conebeam computed tomography. Int Endod J 2009;42:463-75.

14. Liang Y - H , Li G, W esselink PR, W u M-K. Endodontic outcome predictors identified with periapical radiographs and cone-beam computed tomography scans. J Endod $2011 \mathrm{M}$ ar;37(3):326-31.

15. A ndrei $O C, M$ argrait $R, D$ aguci $L$. Treatment of mandibular canine abutment with two canals. Rom J Morphol Embryol. 2010;51(3):565-68.

16. Victorino FR, B ernardes RA, B aldi JV , M oraes IG, B ernardinelli $N, G$ arcia RB, et al. B ilateral mandibular canines with two roots and two separate canals: A case report. Braz Dent J 2009; 20(1):84-86.

17. Heling I, Gottlieb-Dadon I, Chandler NP. M andibular canine with two roots and three root canals. Endod Dent Traumatol 1995; 11(6):301-02.

18. Orguneser $A, K$ artal $N$. Three canals and two foramina in a mandibular canine. J Endod 1998;24(6):444-45.

\section{ABOUT THE AUTHORS}

\section{Prashant P Moogi (Corresponding Author)}

Professor, Department of Conservative and Endodontics, KLE Dental College, B engaluru, Karnataka, India, e-mail: drmoogs@gmail.com

\section{Reshma S Hegde}

Professor, Department of Conservative and Endodontics, K LE Dental College, Bengaluru, Karnataka, India

\section{BR Prashanth}

Senior L ecturer, D epartment of Conservative and Endodontics, K LE Dental College, B engaluru, K arnataka, India

\section{G Vinay Kumar}

Reader, Department of Conservative and Endodontics, KLE Dental College, B engaluru, K arnataka, India

\section{Nandini Biradar}

Postgraduate Student, Department of Conservative and Endodontics KLE D ental College, B engaluru, K arnataka, India 